\title{
Functional Electrical Stimulation as an Orthotic Means for the Rehabilitation of Paraplegic Patients
}

\author{
Rajko Turk, M.D., and Pavla Obreza, P.T. \\ Rehabilitation Institute Ljubljana, Linhartova 51, 61000 Ljubljana Yugoslavia
}

\begin{abstract}
Summary
In rehabilitating paraplegic patients the restoration of locomotion is often planned to enable the disabled person to use the wheelchair as little as possible or eventually even to abandon it. This objective is more easily obtained in those with incomplete spinal lesions. Applied with the view of restoring locomotion are various types of orthoses, but in the present paper the authors deal with functional electrical stimulation (hereinafter FES) as a means of restoring locomotion, demonstrating the advantages of FES over the use of classical orthoses. The paper offers an outline of the methodology of FES in spinal neural lesions, discusses the criteria of patient selection, giving indications and contraindications. The authors conclude by stating their belief that this treatment represents a new way of rehabilitating spinal paralysed patients which will sooner or later become part of the routine rehabilitation of paraplegic patients.
\end{abstract}

Key words: Paraplegia; FES (Functional Electrical Stimulation); Rehabilitation.

\section{Introduction}

The restoration of locomotion represents one of the objectives of rehabilitation for patients with spinal lesions. All over the world various aids have been designed for this purpose. The technical and the aesthetic solutions thereof are sometimes less and sometimes more original, however, all orthotic aids are basically passive orthotic appliances. Patients are sometimes quite injudiciously provided with them, so that they later often abandon them, preferring the wheelchair as the only means of locomotion.

At the Rehabilitation Institute Ljubljana electrical stimulation has been in use for a number of years for different neurological disorders. Producing not only a therapeutic effect but to a certain extent also restoring function; it is referred to as 'functional'. On the whole it is quite difficult to draw a clear demarcation line between therapeutic and functional electrical stimulation.

Electrical stimulation was first merely an object of study but was later developed and researched, and was then used in practice. Thus nowadiays FES may 
be considered to be a practical method for the rehabilitation of paraplegics; and it is well on the way of becoming indispensable in their rehabilitation. It is stressed that this method is not applicable for all lesions nor for all patients, as for medical and other reasons numerous patients are unsuitable for this type of treatment.

\section{FES as an Active orthoses}

Various orthopaedic devices, braces, callipers, straps, and the like are passive orthoses. All the more inefficient are walking apparatuses with external motors which ought to produce i.e. imitate the movement of joints. They all necessitate individual manufacture, are burdensome, and the latter also require a powerful electrical supply, which means that the patient depends on an energy source and is therefore bound by cable connections.

The circumstances present in functional electrical stimulation are quite different. The patient stands and walks by means of his own muscle contraction, the support being secured by his own bones, excursions by his own joints. Contrary to classical orthoses, stimulation via electrodes, which are mostly skin electrodes, implies no individual adaptation or modelling. Skin surface electrodes are fixed by Velcro or similar fixatives. The application and the substitution of electrodes are simple and perfectly independent of the shape and circumference of the extremities.

Stimulation is applied to provoke an active contraction of muscles, to restrengthen the muscles, to enliven metabolism, to prevent atrophy and osteoporosis and to reduce spasticity. In an indirect way numerous complications are considerably mitigated, including, contractures, bedsores, urodynamic disturbances, thrombophlebitis, etc. By FES as an active orthosis favourable psychological effects are also achieved, as well as a direct application independent of orthopaedic technicians.

\section{Methodology in Incomplete Spinal Lesions}

In incomplete spinal lesions with more or less preserved active mobility FES is an almost indispensable rehabilitation method. In such cases it is difficult to distinguish therapeutic stimulation from the functional. Here stimulation means a form of neuromuscular facilitation which in the course of further therapy successfully inaugurates the restoration of locomotion. Stimulation as a method of restrengthening should be started as early as possible after the injury. For an incomplete lesion there is a considerable chance of restrengthening knee extensors to such a degree as to enable the patient to stand by means of his own muscle power. In an attempt to restoring gait stimulation is concentrated upon distal muscle groups, especially the dorsiflexors of the foot. In this type of stimulation a double effect is achieved, namely, dorsiflexion of the foot-drop and a flexor response imitating the swing-phase during gait. Due to this double response the patient can be expected to begin his first steps during the course of further rehabilitation. At the beginning the sequence of stimuli is controlled by the physical therapist, but after rehabilitation has reached an advanced stage, commercially available stimulators with a switch built into the insole of the 
show can be applied. Stimulation is either bilateral or unilateral, depending on the extent of the neurological lesion. The rehabilitation programme can also be composed of hybrid systems, which means that stimulation is applied along with classical orthotic aids.

\section{Method Applied in Complete Lesions}

The restoration of locomotion in a patient with a complete lesion resulting in paraplegia represents a much more serious problem compared to patients with an incomplete lesion. The patient is selected according to the criteria which will now be explained. With proper patient selection we can expect the restoration of standing and, less probably, of gait, even though our experiences includes some paraplegics who are now also able to walk by means of FES.

It is necessary to restrengthen the patient's knee extensors, the quadriceps muscles. By stimulating isometric contractions the patient daily strengthens the quadriceps muscle. At the beginning the responses are weak, the intensity of the response poor, fatigue is immediate. On the basis of clinical and instrumental observations it was found that a bilateral restrengthening of muscles could be achieved in about 2 to 3 months. After obtaining optimal restrengthening results we start initiating the patient into a standing position. At first such standing is for a short duration but by training the patient manages to stand for from 35 to 40 minutes. Reliable standing is also a prerequisite to proceed with rehabilitation with the view of restoring gait.

\section{Indication and Contraindications}

It is of course evident that not all patients suffering from spinal lesions can be subject to an FES programme. A prerequisite for stimulation is the existence of a lesion of the upper motor neuron. This means that patients with flaccid paraplegia are not suitable for rehabilitation by FES. It is desirable that little time should elapse between the injury and the onset of rehabilitation, even though rehabilitation by FES can be possible a number of years after the injury. The reasons why certain patients cannot benefit by the FES program are contractures, heterotopic ossifications, severe spasticity, a poor general state, the age of the patient, high lesions, poor mobility of the spine, deformations, shortened extremities or other serious pathological states. The programme requires a positive psychological attitude of the patient and satisfactory cooperation from him. Following from the above is the fact that as a result of the criteria just enumerated many patients are excluded from the FES programme.

\section{Discussion}

A new method of rehabilitating paraplegic patients is at our disposal, definitely passing from research programmes to practical application. In spite of numerous contraindications, we believe that its importance is no less imposing. One should not forget that as many contraindications are also known for classical orthoses; if prescribed, they are later often discarded. At the present stage of development FES does not incite the hope that patients might totally abandon the use of 
the wheelchair. The current techniques do not enable the patients to stand or walk without supporting himself by his hands. Thus locomotion continues to be bound to the use of parallel bars, walking frames, crutches or at least walking sticks. Much more encouraging results are obtained in the case of patients with incomplete lesions. The application of FES has diminished the number of prescribed classical orthotic appliances. As an active orthosis, FES represents a method for preventing numerous complications, enabling the patient to acquire an ever greater skill in his daily activities.

FES is just one of the aspects of the rehabilitation process, thus it would be wrong to neglect other well known and reliable physiotherapeutic and other rehabilitation procedures. No complications have so far been observed with respect to FES, thus the method is considered to be non-aggressive. However, each paraplegic patient should be studied by taking into account all of his problems, and it is wrong to direct all or most of our efforts to stimulation alone.

By further investigations and due to the knowledge gained in the domain of FES, technical improvements and the development of electrode and microprocessor techniques, FES is achieving success in the rehabilitation of paraplegics, however, at present it is impossible to predict the promises that such stimulation might prove able to fulfil in the future.

\section{Résumé}

Dans de nombreux cas un des buts poursuivis dans la réhabilitation du paraplégique est la restitution de la locomotion pour que l'invalide utilise le fauteuil roulant le moins possible ou bien qu'il l'abandonne totalement. Il est plus facile d'atteindre ce but en cas de lésions incomplètes qu'en cas de lésions spinales complètes. La restitution de la locomotion s'opère à l'aide de differentes types d'orthoses; les auteurs de l'article ci-présent affirment que la restitution de la locomotion se fait aussi par l'intermédiaire de la stimulation électrique fonctionnelle (FES ci-après). Ils comparent les avantages de la FES avec l'application des orthoses classiques. Ils exposent à grands traits la méthodologie de FES en cas de lésions spinales et spécifient les critères imposés dans la sélection des patients, les indications, ainsi que les contre-indications deladite sélection. Ils finissent par souligner leur opinion que la méthode en question représente un mode nouveau de la réhabilitation des patients affligés de lésion spinale et qu'à force de développement elle ne tardera pas à s'intégrer dans la réhabilitation quotidienne des paraplégiques.

\section{Zusammenfassung}

Bei der Rehabilitation des Paraplegikers versucht man in vielen Fällen die Wiederherstellung der Lokomotion zu erreichen, damit der Invalide so wenig wie möglich auf den Rollstuhl angewiesen würde oder sogar darauf verzichten könnte. Dieses Ziel wird leichter bei inkompletten Schäden als bei vollständigen Spinalläsionen erreicht. Zur Wiederherstellung der Lokomotion verwendet man verschiedene Orthosetypen, doch die Verfasser beschreiben in ihrem Beitrag die Möglichkeit der Wiederherstellung der Lokomotion mittels funktioneller elektrischer Stimulation (im weiteren Text: FES). Sie erklären die Vorteile von FES im Vergleich mit der Anwendung von klassischen Orthosen. Im Referat wird die Methodologie von FES bei Spinalschäden beschrieben, ausserdem werden die Kriterien für di Auswahl der Patienten bzw. die Indikationen und Kontraindiktaionen bei der Auswahl der Patienten angegeben. Abschliessend wird hervorgehoben, dass diese Methode eine neue Art der Rehabilitation der Invaliden mit Spinalschäden darstellt, die durch die Entwicklung bald zur alltäglichen Rehabilitation der Paraplegiker gehören wird.

\section{References}

Brindley GS, Polkey CE, Rushton DN 1979 Electrical splinting of the knee in paraplegia. Paraplegia 16:428. 
Crago PE, Peckham PH, Mortimer JT et al. 1974 The choice of pulse duiation for chronic electrical stimulation via surface, nerve, and intramuscular electrodes, Annals of Biomedical Engineering 2:252.

KRALJ A, BAJD T, TURK R 1980 Electrical stimulation providing functional use of paraplegic patient muscles, Medical Progress through Technology 1:3.

Turk Rajko, Kralj A, Bajd T, KRAjnik J, Benko M 1983 Gait restoration in paraplegic patients: a feasibility demonstration using multichannel surface electrode FESa.-J. Rehabil. Res. Dev., New York, 20, 1:3-20.

Turk Rajko, Bajd T, Kralj A, SEga J in H. Benko 1983 Muscle strengthening in paraplegic patients by cyclic electrical stimulation. In: Proceedings of the Third Mediterranean Conference on Medical and Biological Engineering. Portorož, September 5-9, 1983. Ljubljana (ed.) Yugoslav Society of Medical and Biological Engineering and J. Stefan Institute, n. 3.6 (p 2).

Turk Rajko, Kralj A, Bajd T, Rudel D, Benko H 1984 The control of FES enabled gait in spinal cord injured patients. In: Second International Conference on Rehabilitation Engineering combined with the RESNA 7th Annual Conference, Proceedings. Vol. 4., Ottawa, Canada 17-22 June 1984. Bethesda, Rehabilitation Engineering Society of North America 545-546. 